\title{
RACIONALIZAÇÃO E MONETARIZAÇÃO: categorias da globalização
}

\author{
Ulisses do Valle*
}

\begin{abstract}
Este artigo procura analisar alguns aspectos de uma dimensão central do fenômeno frequentemente conhecido como globalização. Trata-se de entender a economia monetária global à luz de duas categorias fundamentais da sociologia: racionalização (Max Weber) e monetarização (Georg Simmel). A partir disso, apresentaremos algumas ideias do sociólogo franco-suíço Aldo Haesler, no que toca às consequências da eletronização dos fluxos monetários que está na base da globalização. Entre outros aspectos, Haesler nos chama a atenção ao correlacionar, de maneira sistemática, três aspectos fundamentais associados à economia monetária global: a invisibilização do dinheiro, a indolorização do sacrifício efetuado nas trocas econômicas, e a dissolução do esquema reciprocitário da ação.
\end{abstract}

PALAvras-CHAvE: Racionalização. Monetarização. Dinheiro. Globalização. Aldo Haesler.

Este texto pretende avançar em algumas reflexões sobre uma dimensão central do fenômeno recente que se convencionou chamar de globalização. O conceito de globalização é um conceito de tal forma amplo e multifacetado, que sobre ele paira, quando não uma reiterada confusão, ao menos certa nebulosidade que inviabiliza, de uma só vez, concentrar-se sobre todas as características fundamentais do fenômeno que procura expressar. Em geral, globalização se refere ao processo de integração cultural, social, espacial e econômica de estruturas que, em tempos anteriores, restringiam-se a contextos locais e nacionais. A globalização, nesse sentido, diz respeito à própria criação de estruturas transnacionais que, como tal, dissolvem o paradigma do Estado-nação como epicentro das abordagens sociológicas, históricas e (ou) políticas a serem realizadas. O termo se tornou corrente nas ciências humanas e no vocabulário jornalístico em geral, principalmente a partir da queda da URSS e da consequente expansão e integração crescente dos

* Universidade Federal de Goiás. Faculdade de História. Avenida Esperança, s/n, Campus Samambaia. Cep: 74.690900. Goiânia - Goiás - Brasil. ulissesv@ufg.br padrões de produção, circulação e consumo de bens econômicos e culturais.

Abordaremos um setor específico do mundo globalizado, a saber, a economia monetária, remetendo sua análise a categorias oriundas da sociologia clássica. Nesse caminho, podemos dizer que estamos aceitando a sugestão já dada por um dos pioneiros no estudo da globalização no Brasil, Ianni (2001, 2004). É que também Ianni (2001, p. 156) esteve inclinado a associar o fenômeno da globalização ao fenômeno da racionalização. Mas nem isso livrou completamente Ianni de certa confusão entre conceitos que, mais tarde, Ulrich Beck recomendaria enfaticamente diferenciar: globalização, que aparece em livro publicado originalmente em 1995, intitulado Teorias da Globalização (2001), e globalismo, que aparece em livro publicado um ano depois, com o título $A$ Era do Globalismo (2004). Para Beck (2002, p. 23), globalismo se refere ao domínio neoliberal do mercado mundial, enquanto globalização, mais amplo, se refere ao processo supracitado de integração cultural, social e espacial, além de econômica. Essas são classificações que se focam em elementos propriamente espaciais 
do fenômeno da globalização. Alguns autores, como Fredric Jameson, em A Cultura do Dinheiro: ensaios sobre a globalização (2002), e Antony Giddens, em As consequências da Modernidade (1991)- livro ao qual retornaremos adiante -, esboçam uma compreensão epocal da globalização, conectando-a a conceitos tão controversos quanto o de globalização, como é o caso de pós-modernidade, salientado por Jameson (2002, p. 96). Se há algo comum a todos esses autores, entretanto, é o fato de considerarem que a globalização, por mais multifacetada que seja, esteve sempre conectada, simultaneamente, à racionalização e à monetarização das relações sociais.

A ideia é evidenciar os conceitos de racionalização e de monetarização como categorias da globalização: isto é, o de mostrar que só se entendem algumas dimensões fundamentais da globalização se, antes, se entender o que vem a ser aquilo que, com Max Weber, chamamos de racionalização, e aquilo que, com Simmel, chamamos de monetarização. Não se trata, portanto, de compreender a globalização como uma extensão da racionalização e da monetarização. Diferentemente, o propósito é o de esclarecer aspectos fundamentais da globalização à luz daquelas duas categorias sociológicas. O conceito weberiano de racionalidade formal bem como a noção de Simmel de monetarização da vida serão postos a serviço do esclarecimento de uma das principais dimensões da globalização - a economia monetária global. Com isso, evidenciaremos a monética e as novas técnicas monetárias como o fator essencial de racionalização formal, o qual está na base de uma economia global, destacando algumas consequências imediatas desses fenômenos. Seguiremos, assim, com uma análise do conceito de racionalidade em Max Weber, para, depois, passar à caracterização de Simmel da economia monetária, chegando, por fim, aos estudos recentes de Aldo Haesler quanto à eletronização dos fluxos monetários. Esse propósito se alinha, por isso, a concepções mais recentes do estudo da globalização, que atestam, ao lado da novidade dos seus traços perceptíveis, sua historicidade, isto é, o fato de ela estar vinculada a processos do passado já estudados pela sociologia clássica. O próprio Urich Beck (2002), em livro supracitado, propõe tratar o contexto da globalização como uma segunda modernidade, oferecendo, assim, uma alternativa aos impasses criados pelo conceito de pós-modernidade.

O procedimento que adotamos, portanto, supõe um tema de fundo - um quadro de problemas - que é comum aos três autores supracitados, qual seja, a caracterização e a análise do capitalismo entendido como um cosmos cultural e institucional que, de maneira crescente, configura uma sociedade globalmente integrada segundo relações e princípios dos quais as mais graves consequências são aquelas que levam à despersonalização da ação humana. É a partir do quadro de problemas colocados pelo tema do capitalismo que categorias sociológicas desenvolvidas por autores tão diferentes como Weber, Simmel e Haesler podem ser postas num horizonte de convergência. Note-se que é de quase um século a diferença cronológica dos contextos de Weber e Simmel, por um lado, e de Haesler, por outro. Essa distância temporal, entretanto, não anula e nem deve obscurecer a proximidade temática. Como pretendemos apontar, ainda que do contexto de Weber e Simmel até o de Haesler o capitalismo tenha se transformado bastante, pelo menos dois de seus princípios fundamentais continuam os mesmos: a racionalização formal e a monetarização. O que permite que as análises desses três autores sejam apanhadas conjuntamente consiste no fato de que todos eles consideraram o capitalismo como algo muito mais amplo que um sistema econômico - ou, se quisermos, um sistema econômico que, dada sua incrível capacidade de determinar as condutas humanas, se converte numa espécie de meta-valor da cultura, que passa a coordenar, de maneira crescente, todas as demais esferas ou ordens de valores que compõem a vida em sociedade - a política, 
a religião, o conhecimento, a arte, a sexualidade, etc. - e cuja existência, já para Weber e Simmel, parecia mais inquebrantável do que gostavam de admitir os diversos proponentes das utopias anticapitalistas. ${ }^{1}$ Vejamos, então, como as análises de Weber e Simmel podem ser dirigidas, com a ajuda de Haesler, para uma reflexão sobre novas técnicas monetárias do capitalismo contemporâneo.

\section{MAX WEBER E O TEMA DA RA- CIONALIDADE DO CAPITALISMO}

Max Weber (1964-1920) desenvolveu uma abrangente pesquisa genealógica dos princípios de conduta que constituem os padrões éticos fundamentais disseminados na cultura ocidental. Em sua sociologia da religião, Weber desenvolveu um longo estudo comparativo entre a trajetória das grandes civilizações mundiais e, a partir disso, tentava evidenciar as especificidades da cultura ocidental que lhe possibilitaram a constituição do capitalismo como modo de vida e visão de mundo.

Em ensaio primeiramente publicado em 1964, Herbert Marcuse (2009) empreende uma leitura de Weber que praticamente ignora o conjunto de sua sociologia da religião. Marcuse dá uma boa descrição do que Weber chamara de racionalidade formal, evidenciando seu caráter instrumental em relação ao homem e à natureza, na qual prevalece, mais do que os melhores meios para se alcançarem fins já determinados, a aplicação de regras técnicas para sua consecução. O fato fundamental que singulariza o caráter instrumental da racionalidade formal - que, como veremos, mantém

${ }^{1}$ Ao final da A Ética Protestante e o "Espírito" do Capitalismo,Weber(2007) chega a dizer que, uma vez constituído como sistema, apenas quando a última gota de combustível fóssil fosse queimada é que o capitalismo seria destruído. Embora soasse demasiadamente pessimista, a assertiva de Weber tem se mostrado não tê-lo sido suficientemente. O próprio capitalismo e o desenvolvimento tecnológico a ele correlato criaram formas de energia substitutivas e até mais potentes que os combustíveis fósseis - é como se a tragédia da cultura, apontada por Simmel em conexão com a monetarização da vida, tivesse um novo capítulo, e, mais uma vez, salientasse o caráter criador da subjetividade humana degenerando-se em produtos estranhos a ela. o maior grau de afinidade com as exigências produtivas do capitalismo - consiste na redução do homem e da natureza ao estatuto de ser, meramente, mais uma variável no cálculo e na avaliação (técnica) das chances de êxito e lucro, disso derivando sua negação da vida ou, nos termos de Weber, sua rejeição do mundo. A esse respeito, diz Marcuse (2009, p. 158):

\footnotetext{
O modo 'formalmente mais racional' de contabilidade do capital é aquele no qual o homem e seus 'propósitos' entram apenas como variáveis no cálculo das oportunidades de ganho e lucro. Nesta racionalidade formal, a matematização é levada ao ponto do cálculo com a 'negação real da própria vida'.
}

Marcuse (2009), entretanto, parece não perceber que, no modelo de análise weberiano, o conceito de racionalidade instrumental corresponde a uma função particular dentro do panorama geral de sua tipologia da racionalidade e, além disso, corresponde, como tal, a um tipo ideal, a uma imagem formulada segundo orientação teórica e com fins heurísticos, da qual a realidade pode se aproximar em maior ou menor grau, mas nunca corresponder. A análise de Marcuse, com isso, além de impossibilitar uma compreensão da especificidade da racionalidade instrumental em relação aos outros tipos fundamentais, simplifica algo demasiado complexo que é o processo de racionalização em suas variadas direções e ritmos específicos.

O tema da racionalização atravessa toda a obra de Weber. ${ }^{2}$ Racionalização é, antes de qualquer coisa, uma forma de desenvolvimento do processo histórico. Essa forma de desenvolvimento do processo histórico é, por sua vez, devedora do conjunto de capacidades humanas que tomam, em Weber, a dimensão do que ele chama de racionalidade. Ela diz respeito, de maneira geral, a capacidades universais da espécie humana, que singularizam o humano como um animal à parte. Só se entende a multiplicidade do processo de racionalização

${ }^{2}$ Centrais para o entendimento do conceito de racionalização na obra de Weber são Löwith (2007), Habermas (1999), Kalberg (1980), Schluchter (1981) e Sica (2004.) 
se, antes, se entender a multiplicidade da racionalidade como conjunto de capacidades que especificam a ação do homem na história. $\mathrm{Na}$ base dos escritos de Weber está uma filosofia da cultura que encontra, no sentido e na simbolização, na capacidade de significar, a unidade analítica da cultura. É por isso que a base da sociologia compreensiva de Weber é a distinção entre comportamento e ação. É a capacidade de dar significado à experiência o que, em última instância, se entende por racionalidade, no sentido mais amplo que Weber lhe dá. O homem, genericamente falando, é o animal que pensa, é o animal que trabalha, é o animal que conhece a morte e sofre com sua angústia; sim, mas nada disso o faria se, antes, não fosse o animal symbolicum, capaz de manipular significados por meio de símbolos e signos. Alguns comentadores recentes da obra de Weber, como Ciaffa (1998) e Koshul (2005) tentaram precisar esse traço essencialista da filosofia da cultura weberiana sob a classificação do homem como homo-hermeneut, uma convicção segundo a qual "os humanos têm a necessidade interna, tanto quanto a capacidade, de interpretar suas vidas e o cosmos como um todo de uma forma significativa” (Koshul, 2005, p. 83). É, pois, a capacidade de dar um sentido e uma significação àquilo que está na base daquele "segmento finito da infinidade sem sentido dos eventos iे do mundo" que Weber nomeia como cultura $\stackrel{\infty}{\infty}$ (Weber, 2012b, p. 119). Central à sociologia weberiana, por isso, é a distinção entre comportamento e ação. Enquanto a ação corresponde a uma conduta autorreferida, a um sentido atribuído pelo sujeito agente, o comportamento ¿. corresponde a uma conduta não intencional,

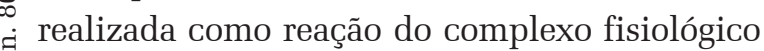
iे aos estímulos externos e internos (Weber, 2004, p. 4). É, pois, a capacidade de atribuir sentido à própria conduta que Weber nomeia com o signo geral de racionalidade.

Esse ponto põe em destaque, então, um princípio antropológico que distingue o comportamento humano de sua herança animal, por um lado, e funda o âmbito existencial de uma cultura frente à natureza sem sentido, por outro. Na base de todas as insondáveis diferenças interculturais, existe um princípio comum, que é duplamente fundante da cultura: a capacidade de simbolizar a própria experiência e de administrá-la por meio de símbolos, o que funda a um só tempo, o reino da ação e da cultura em fluída oposição ao reino do comportamento e da natureza. E, somando-se a isso, é essa mesma capacidade de dominar a realidade contingente por meio de símbolos que permite que os sentidos e os significados sejam também, eles mesmos, tematizados, isto é, tornados objeto de inquirição de uma ciência da cultura. ${ }^{3}$

Ora, racionalidade, assim, está longe de ter surgido em paralelo ao capitalismo, como queria o Esclarecimento (Aufklärung) oitocentista, a rósea galhardia do capitalismo triunfante (WEBER, 2007 p. 165); e mesmo a orientação para o êxito (entendido como minimização dos custos para a consecução de um fim) da racionalidade instrumental, que se tornaria o padrão reificado de atribuição de sentido no interior da modernidade cada vez mais dominada pelas premissas do capitalismo, originou-se muito anteriormente a qualquer período que por nós possa ser datado. Racionalidade e ação são duas categorias inseparáveis no modelo weberiano de sociologia. É a partir dos diferentes modos de atribuir sentido à própria conduta que Weber estabelece uma tipologia da ação e dela deriva uma tipologia da racionalidade.

É por isso que, na tipologia da ação de Weber, ocupa um espaço importante a distinção entre o comportamento orientado por um sentido (ação) e o comportamento reativo. Tais tipos estão situados, diz Weber, não como exatos opostos: a relação não é exatamente polar, mas gradativa; é impossível distinguir com

${ }^{3}$ É esse, pois, o sentido da famosa passagem de Weber quando diz que a premissa transcendental de uma ciência da cultura reside "na circunstância de sermos homens de cultura, dotados da capacidade e da vontade de assumirmos uma posição consciente em face do mundo e de lhe conferirmos um sentido" (Weber, 2012b, p. 119). Daí se entende o fato de uma antropologia filosófica caminhar lado a lado com uma filosofia da cultura ou, em outras palavras, o fato de, em Weber, não haver uma distinção clara entre esses dois âmbitos de indagação. 
exatidão os limites entre um e outro. Por um lado, mesmo a mais racional das ações é apenas parte de um comportamento global que ultrapassa a significação atribuída pelo agente, de tal modo que o homem, a despeito de sua racionalidade, não se livra da carga afetiva e instintiva (e irracional) da qual se desprende todo o seu agir segundo um sentido. Mas, ainda quando esse sentido subjetivamente visado está ausente, em muitos casos é possível compreender uma conexão de sentido entre a identificação de um afeto e a ação de alguém: então dizemos "fulano agiu por raiva ou ódio", ou por "pânico ou desespero". Esse tipo de conexão identificável entre afeto e comportamento diz respeito ao que Weber chamara de comportamento afetivo. Ele é o limiar do complexo convívio de cultura e natureza na constituição humana, um ponto que está no limite ou além de uma ação orientada pelo sentido:

O comportamento estritamente afetivo está [...] no limite ou além daquilo que é ação conscientemente orientada 'pelo sentido'; pode ser uma ação desenfreada a um estímulo não cotidiano. Trata-se de sublimação, quando a ação afetivamente condicionada aparece como descarga consciente do estado emocional: nesse caso encontra-se geralmente (mas nem sempre) no caminho para a 'racionalização' em termos valorativos ou para a ação referente a fins, ou para ambas (Weber, 2004, p. 15).

Esta passagem concentra grande parte do nosso interesse em Weber para os fins deste artigo. Ela torna mais explícito o denso conflito interno entre racional e irracional, entre racionalidade e irracionalidade. A sublimação do comportamento afetivo em direção a uma reorientação consciente é o primeiro passo da racionalização. Racionalização é, então, uma maneira de descrever a experiência histórica do homem no que toca à crescente sistematização e administração da experiência contingente do mundo por meio de significados e símbolos culturais (que podem, entre outras coisas, se cristalizar em normas ou formas institucionais). A racionalização é de caráter prático, se visar tão somente à adaptação de meios às soluções de problemas da vida cotidiana. Ou ainda, de caráter teorético, se ela visa a dominar a experiência através do pensamento abstrato e da formação e sistematização de conceitos. A racionalidade teorética, como tal, é aquela que apenas indiretamente redunda na criação de padrões de ação (Kalberg, 1980, p. 1153). Ela, por isso, não é menos importante: ao contrário, a sistematização que oferece da conduta global de determinada comunidade cultural corresponde àquelas que, em muitos casos, podem ser as mais prenhes de consequências ulteriores para a ação (como é o caso das doutrinas teológicas do protestantismo ascético, por exemplo). O domínio da racionalidade teorética, além do mais, sempre exigiu a participação ativa de um corpo especializado de "virtuosos", assim distinguidos das massas não qualificadas à abstração reivindicada: do mago, passando pelo sacerdote até chegarmos ao cientista moderno, existe um princípio comum que consiste justamente na constituição interna de uma ética dos virtuosi em oposição às massas, aos membros comuns daquela comunidade (Schluchter, 2010, p. 92-93).

Uma vez que essa racionalização parte sempre de uma base afetiva, instintiva, irracional, não há, em Weber, um estândar absoluto de racionalidade. Um dos maiores alvos de Weber, sem dúvida, foi mostrar a variedade de padrões culturais e históricos implicados na expressão "ser racional". No contexto geral de sua obra, um padrão de racionalidade só se define em correlação à arbitrária exclusão de elementos que, de um ponto de vista específico, e jamais unívoco, são irracionais. As mais diversas culturas, portanto, produzem distintos modelos do que, internamente a elas, constituem tomadas de posição adequadas em termos de sentido (racionais), em contraposição àquelas cujo sentido é ininteligível ou ausente (irracionais). A racionalização, desse modo, é um processo que pode abranger várias esferas da vida e é a própria incompatibilidade das constelações valorativas, dos padrões de racionalidade, o fator fundamental que gera irracionalidades. 
Existem, por exemplo, 'racionalizações' da contemplação mística, isto é, de uma atividade que, vista a partir de outros âmbitos da vida, é especificamente 'irracional', assim como existem racionalizações da economia, da técnica, do trabalho científico, da educação, da guerra, da justiça e da administração. Além disso, cada um destes âmbitos pode racionalizar-se a partir de pontos de vista e objetivos últimos da maior diversidade, e o que é visto a partir de um como 'racional' pode ser irracional visto de outro. De modo que têm existido racionalizações dos tipos mais diversos nos diferentes âmbitos da vida em todas as culturas (Weber, 1992, p. 21).

Essa é a marca do perspectivismo radical de Weber. Uma vez capaz de simbolizar a própria experiência, o homem também pôde, a partir disso, representar a própria conduta e projetar o próprio comportamento em função da representação de um êxito futuro (o fim da ação), ou em razão do cumprimento de um dever. No primeiro caso, falamos de uma ação racional com relação a fins; no segundo, de uma ação racional com relação a valores. No quadro geral da tipologia weberiana, a ação racional assume um caráter derivado e tardio em relação ao comportamento afetivo, por um lado, e ao comportamento tradicional (como a imitação reativa), por outro, ambos não racionais. Mas o que é importante destacar aí é que o processo de racionalização que leva de um comportamento não racional à sistematização ऽे. da conduta em torno de um padrão valorativo \& arbitrário (no sentido de que poderia ser outro) cria, concomitantemente e contiguamente, a esfera negativa de uma dimensão irracional, heterogênea ao valor a partir do qual a ação foi racionalizada. Pois se um valor, como diz $\therefore$ Schluchter (2010, p. 93), pode ser definido ¿ como "uma concepção de validade que se tor\& na causa de uma ação", é a própria incompa$\therefore$ tibilidade entre concepções últimas de validade o que define, em Weber, aquilo que é irracional. O irracional, assim, pode ser descrito como uma zona obscura, criado pelo conflito de constelações últimas de valores (Weber, 2012a, p. 314-315).

Postulados substantivos de valor, assim, podem ser racionalizados tanto de maneira prática, adaptados às dimensões do interesse pessoal e às condições históricas particulares nas quais se exercem tais valores, quanto teoreticamente, visando a uma maior consistência lógica entre ideias e ação, isto é, a uma maior coerência e sistematicidade dos postulados de valor com sua prática existencial. Assim, a diversidade de valores substantivos às quais correspondem as mais diversas constelações culturais pode ser racionalizada tanto num sentido prático, quanto num sentido teorético. Enquanto o primeiro caso de racionalização conduz a processos de adaptação prática, de adequação gradual de meios a fins aceitos e absolutizados, a segunda conduz a um processo de confrontação cognitiva com a experiência, caracterizando-se por um domínio conceitual da experiência através da abstração e da sistematização crescente de seus componentes iniciais em relação aos postulados valorativos. É perfeitamente possível, nessa medida, que um padrão de racionalidade substantiva sofra um processo de racionalização teorética, ganhando maior clareza e coerência conceituais.

Ora, o que Weber chama de racionalidade substantiva corresponde a um tipo de significação da conduta que foi abstraída, sistematizada, representada (racionalizada) em torno de uma convicção valorativa, cuja aparência fenomênica é geralmente representada por parte do ator na forma de um dever a ser cumprido através da ação. Ela difere da racionalidade prática na medida em que, em sua base, não está um cálculo puro entre meios e fins para solucionar problemas cotidianos, mas em relação a um potencial postulado de valor, passado ou futuro (Kalberg, 1980, p. 1155). O que é para nós mais importante no que toca à racionalidade substantiva é enfatizar o pluralismo potencial que está no seu fundamento. É esse "politeísmo dos valores" que assegura a multidimensionalidade do processo de racionalização. É, por isso, incabível a interpretação de Marcuse, segundo a qual Weber havia identificado a racionalidade formal do capitalismo 
com a racionalidade em termos amplos. Tal asseveração demonstra a simplificação absurda que Marcuse faz da tipologia weberiana da racionalidade.

A racionalidade formal, para Weber, é, entre todos, o tipo mais tardio na experiência humana. Seu surgimento dependeu de condições de existência que só ganharam vida e difusão suficiente no Ocidente em vias de modernização. Embora Marcuse siga Weber na caracterização da racionalidade formal que viria a se tornar o metavalor da cultura ocidental, ele parece não perceber a ligação contingente que esse modelo de racionalidade guarda, em suas origens, com postulados de valor oriundos da racionalidade substantiva da ascese intramundana da religiosidade protestante. Nos seus estudos empíricos de sociologia e história da cultura, Weber localiza a gênese da ideia do trabalho profissional mundano como um dever moral, como um valor, no seio da ascese protestante.

A valorização moral e religiosa do trabalho, bem como a racionalização da vida como um todo a partir desse valor, corresponde ao estado ético que apraz, em bloco, às doutrinas fundamentais do protestantismo ascético. Ela é, como tal, um tipo de racionalidade substantiva, e não formal. O que Weber demonstra, na Ética Protestante e o Espírito do Capitalismo, é que a tendência à despersonalização, que caracteriza a racionalidade formal, surgira, primeiro, como uma espécie de demanda ética (valorativa) da doutrina da predestinação calvinista, cuja radicalização da concepção de um Deus transcendente levara também à impossibilidade de o indivíduo participar ativamente da própria salvação. Assim, o postulado de valor calvinista, segundo o qual as relações pessoais ganham um caráter pecaminoso que desagrada a Deus, é a base na qual se sedimentam os vínculos sociais de solidariedade do que seria um tipo puro de organização social calvinista. Quanto à tendência à impessoalização e despersonalização do agir, como postulado de valor das doutrinas calvinistas, diz Weber (2007, p. 208-209, grifo do autor):
Aqui foi decisiva a crença de que o cristão comprova seu estado de graça atuando in majorem Dei gloriam, e a aguçada execração da divinização da criatura [e de todo apego a relações humanas pessoais] não tinha como não canalizar essa energia, imperceptivelmente, para os trilhos da ação objetiva (impessoal). [O cristão que toma a peito a comprovação de seu estado de graça age para os fins que são de Deus, e estes só podem ser impessoais.] Toda relação pessoal de caráter puramente sentimental e, portanto, não condicionada racionalmente - de pessoa para pessoa incorre muito facilmente na suspeita, aos olhos tanto da ética puritana como de toda ética ascética, de cair em divinização da criatura[...].

Weber (2007) destaca, ainda, quatro esferas fundamentais, além da economia, as quais seriam imediatamente atingidas por essa tendência à despersonalização: a esfera estética, a esfera erótica, a esfera gnosiológica e a esfera política. Às três primeiras afetam um elemento comum: a recusa de toda a "cultura dos sentidos em geral". Os sentidos e o elemento sensualista da cognição passam, de uma vez por todas, a serem rebaixados e tornados índices de pecaminosidade que desviam o homem da exigência de uma ordenação objetiva da vida em torno de sua vocação profissional mundana. Essa relação conflituosa da moralidade calvinista com os elementos sensualistas da cognição humana, aspecto fundamental do seu tipo particular de rejeição do mundo, viria, posteriormente, a ser "selecionada" pelo cosmos institucional - a empresa e o Estado (e o laboratório, deve-se acrescentar) modernos -, presidido pela racionalidade formal. Daí advém, inclusive, a fonte de toda angústia weberiana frente ao processo de racionalização. Sob a égide de um formalismo que se torna autônomo em relação a todos os valores substantivos, o processo de racionalização fundamenta-se na quantificação e na matematização dos elementos concretos da experiência humana; trata-se de um processo de legitimação da ordem formal a partir da despersonalização operada pela aplicação de regras tecnicamente regulamentadas. Sua legitimação política sequer depende do uso direto da força, porque o 
cumprimento de uma ordenação impessoal do mundo implica a crescente disciplinarização da conduta em torno do princípio fundamental da racionalidade formal: a maximização dos êxitos (lucro) e a otimização dos recursos disponíveis (meios).

Portanto, a racionalidade formal é tardia em relação aos demais tipos de racionalidade. Enquanto a racionalidade prática (domínio da realidade através da adaptação gradativa dos meios em relação aos fins), a racionalidade teorética (domínio da realidade através de pensamentos e conceitos) e a racionalidade substantiva (domínio da realidade através de sua submissão a postulados de valor) têm um caráter intercivilizacional e extratemporal, a racionalidade formal relaciona-se a esferas da vida e a uma estrutura de dominação que só se tornam claras com a industrialização (Kalberg, 1980, 1158). Sua estrutura primordial é o cálculo dos melhores meios para a consecução de fins dados e não questionados, cálculo que deve atender às prescrições dos regulamentos de caráter técnico. Tal como a racionalidade prática, a racionalidade formal também se caracteriza pela adaptação de meios em relação a fins. Diferentemente dela, entretanto, a racionalidade formal tem como referência não um inح teresse pragmático no êxito pessoal, mas, ao contrário, baseada em regras, leis ou regulamentos universalmente aplicados, a racionalidade formal caracteriza-se, paradoxalmente, por um tipo particular de despersonalização da conduta. A abstração crescente significa, no âmbito da racionalidade formal, o afastai.

maça e uniformização da experiência como meio de facilitar o cálculo para a maximização dos fins.
Este é, aliás, o fato fundamental de legitimação desse tipo de racionalidade: ao se desvincular da experiência pessoal por meio da abstração generalizante, as exigências da racionalidade formal são legitimadas por uma espécie de tautologia imanente, como observa Castoriadis (2004), num sentido muito próximo ao de Marcuse. Esta tautologia é a base de um modo de legitimação da ordem muitíssimo mais eficaz do que o poderia ser qualquer dominação de caráter pessoal, seja de ordem carismática, ou imposta pela força de um exército pessoal. Sua contenção dos impulsos não precisa recorrer à força externa, porque ela deriva da própria resposta interna dada pelos indivíduos a seus impulsos de transgressão da ordem: a estrutura de dominação é interiorizada e exerce, nessa medida, um controle adscrito à própria formação da identidade dos atores sociais. Despersonalizados pela racionalidade formal, o sentido de sua conduta confunde-se, ele próprio, com o da ordem objetiva da racionalidade formal, de tal maneira que se torna cada vez mais difícil voltar a distinguir, nos atores sociais, as qualidades que faziam deles sujeitos. ${ }^{4}$

A partir do princípio fundamental da racionalidade formal, qual seja, a aplicação de um ordenamento normativo de caráter técnico-jurídico, a crença e a aceitação de uma ordenação impessoal e "objetiva” da vida, é possível identificar suas afinidades eletivas com uma estrutura de dominação peculiar aos desdobramentos posteriores ao capitalismo industrial. Weber, no ponto alto de suas investigações, esboça uma ampla genealogia do racionalismo ocidental e, dentro dele, diz Weber, do racionalismo ocidental moderno (Weber, 1992, p. 21). Caracterizar a especificidade sociocultural do racionalismo ocidental significa, para Weber, analisar "em que esferas e em quais direções se racionalizaram” os prin-

\footnotetext{
${ }^{4}$ Castoriadis (2004, p. 101) descreve o processo de racionalização levando à formação de um novo tipo antropológico: não mais o homo-hermeneut, de Weber, mas o homo computans, o animal que calcula. A racionalidade formal, que preside o homo computans, altera, de modo fundamental, a multiplicidade temporal: "A duração é reabsorvida no tempo mensurável, imposto a todos”.
} 
cípios valorativos de seu sistema de conduta. A racionalização que caminha na direção da racionalidade formal penetra em várias esferas da vida no Ocidente moderno: da organização racional-burocrática do trabalho na fábrica à ordenação e unificação jurídica do Estado Moderno. Caminha também em direção à esfera gnosiológica (reduzindo ciência a positivismo lógico), elevando a técnica a um meio universal e central a todas as esferas da vida. Ora, a racionalização formal - está nisso correto Marcuse - segue a direção de:

a) uma matematização progressiva da experiência e do conhecimento que, com o apelo do extraordinário sucesso das ciências naturais, se estende também a outras ciências e à conduta de vida em si mesma;

b) uma institucionalização da ciência e seu método de experimentação racional como espaço privilegiado de prognósticos técnicos ao agir e às decisões; $\mathrm{e}$

c) da organização burocrática como princípio societário generalizado, como princípio de disciplinarização da conduta (Marcuse, 2009, p. 153).

Ora, esse quadro de princípios derivados da racionalidade formal encontrou, na empresa capitalista, e, veremos, também no processo de circulação de mercadorias, as condições ótimas para se tornar dominante no quadro do capitalismo global. A seguir, apresentaremos a caracterização filosófico-sociológica que Simmel dá do dinheiro como mediador das trocas sociais, ressaltando as afinidades entre economia monetária e racionalização formal. Com isso, teremos condições de apresentar o sombrio diagnóstico oferecido por Aldo Haesler (1995) quanto às consequências da eletronização dos fluxos monetários ou, em outras palavras, do aparecimento da monética como tecnologia fundamental da economia do hipermercado global, evidenciando os vínculos entre racionalização formal e desmaterialização e invisibilização do dinheiro, suportes essenciais do recente fenômeno da mundialização e globalização do capitalismo.

\section{SIMMEL E HAESLER: a monetari- zação da vida e o tornar-se conceito do dinheiro}

Se, por um lado, o comportamento individual com sentido era a base da sociologia compreensiva de Weber, Simmel é hoje reconhecido por ter definido outro elemento de base para a sociologia: no caso, diz Haesler (1995, p. 127), "a reciprocidade que age no entre-nós humano”, a troca entre partícipes de uma interação. A palavra alemã Wechselwirkung, às vezes traduzida como interação, designa uma forma de relação social que encontra na troca (Wech) entre partícipes o fundamento último da sociedade. Nisso, ele foi muito mais longe do que Weber, que definiu a ação social como aquela cujo sentido se refere ao agir de outros, presentes, passados ou futuros, conhecidos ou anônimos. ${ }^{5}$ Simmel não distingue exatamente entre o sentido individual de cada partícipe da relação social, mas se fia no elo simbólico firmado entre eles através de sua ação recíproca (tal como é traduzido o termo Wechselwirkung para o francês - "action réciproque" ${ }^{6}$ ).

Ora, se a troca é vista por Simmel como o fundamento primeiro da sociedade, é claro que tomará aí uma importância capital o conceito de troca econômica. Desde suas origens, é através do sacrifício que a troca, forma mais geral do jogo social, torna-se econômica. A distinção, embora sutil, é essencial para a sociologia simmeliana. A troca econômica, nos seus primórdios, envolve o sacrifício de um objeto, de um dom (dádiva) que não voltará mais. É a própria tensão entre sacrifício e comparação dos objetos trocados que define a "economicidade" da coisa. Pode-se dizer que toda troca econômica (Austausch) é também simbólica, porquanto nem toda troca simbólica seja ne-

${ }^{5}$ Destaca-se, aí, o acento dado por Weber (2004, p. 13 e 14), em conformidade com as concepções de Simmel, do dinheiro como forma de relação social na qual os outros são pressupostos em sua anonimicidade: aceita-se o dinheiro sob o pressuposto e a confiança (crença) de que outros o aceitarão de volta no futuro.

${ }^{6} \mathrm{Na}$ tradução para a língua inglesa, que utilizamos aqui, essa oposição aparece como Exchange versus Interaction. 
cessariamente econômica. Embora os partícipes de uma ação recíproca (interação social), de uma troca simbólica, saiam dela sempre mais "ricos" do que quando a iniciaram, a troca econômica implica o sacrifício de um objeto para adquirir outro. Diz Simmel:

Deve-se reconhecer que a maioria das relações entre
as pessoas podem ser interpretadas como formas de
troca. A troca é o mais puro e o mais desenvolvido
tipo de interação, que modela a vida humana assim
que ela adquire substância e conteúdo. [...] Toda in-
teração precisa ser vista como uma troca: toda con-
versação, toda afeição (mesmo se rejeitada), todo
jogo, todo olhar para outra pessoa. A diferença que
parece existir, de que em uma interação uma pes-
soa oferece o que ela não possui enquanto na troca
ela oferece apenas o que ela possui não se sustenta.
Pois, no primeiro plano, é sempre a energia pessoal,
a renúncia/entrega da substância pessoal que está
envolvida na interação; e, inversamente, a troca não
é conduzida por causa do objeto que a outra pessoa
possui, mas para recompensar os sentimentos pes-
soais de alguém que ele não possui. [...] O cotidiano
de nossas vidas compreende um processo de ganho
e perda, de acréscimo e diminuição de conteúdo de
vida, que é intelectualizado na troca a partir do mo-
mento em que a substituição de um objeto por outro
se torna consciente (Simmel, 2004, p. 79-80).

Dada a caracterização da troca como forma fundamental das relações sociais, o ponto fundamental, para nós, é a mudança impleF mentada pela disseminação do dinheiro como N mediador fundamental das trocas, bem como $\dot{8}$ o processo de racionalização que se verticali$\sum^{\pi}$ za nessa esfera, nomeado por Simmel como monetarização. O fundamental do processo de monetarização, diz Haesler (1995), é que as trocas deixam gradativamente de ser regidas pela lógica do dom, da troca enriquecedora de energias e dádivas pessoais, para ser cada vez mais dominadas pela racionalidade formal da ógica monetária. Ora, esse processo de racionalização segue da disseminação da nominalização do valor da moeda (que perde lastro material) até a invenção da monética, da eleronização e da digitalização cifrada dos fluxos monetários - de sua invisibilização.

Com a abertura das economias no fim do período medieval, o dinheiro se tornou o elemento fundamental e necessário de facilitação das trocas. Com o aparecimento gradativo do dinheiro nos espaços culturais, desaparecia, concomitantemente, a tradicional forma de posse: com o crescimento do dinheiro, crescia também seu "poder de objetificação", de separação entre bens e pessoas. A posse, com a monetarização das trocas, deixa de ter caráter pessoal e se impessoaliza. Nisso consiste já uma primeira afinidade com a racionalidade formal. A monetarização permite, entre outras coisas, uma nova forma de posse, que prescinde da ligação com uma personalidade em particular.

Estas conexões entre personalidades e relações objetivas - conexões típicas nestes tempos de economia natural - desfaziam-se na economia do dinheiro. Esta última interpõe em cada instante, entre pessoa e coisa definitivamente qualificada, a instância totalmente objetiva e não qualitativa em si mesma do dinheiro e do valor monetário. Ela impõe uma distância entre pessoa e posse, tornando a relação entre ambas mediada. Ela diferenciou, com isso, a relação anteriormente tão íntima entre elementos pessoais e locais, [...] (Simmel, 1998, p. 25).

Ora, esse elemento de impessoalidade, conferido pelo valor monetário, que um objeto passa assumir como mercadoria está em completa afinidade com o princípio de cálculo da racionalidade formal. O dinheiro realiza a tendência, já revelada por Marx, de unificar o diverso - a riqueza fenomenal da coisa é reduzida a seu valor de troca. A abstração monetária subtrai às coisas as suas qualidades derivadas das relações e significações humanas, reduzindo-as à quantidade de um único valor: o monetário. A princípio, esse cálculo de quantidade, feito com base no valor de troca, definir-se-ia em função da escassez e abundância relativa das mercadorias trocadas entre diferentes partes da interação. A racionalização formal, sustentada com o apoio técnico da monetarização das trocas, leva a uma alteração profunda dessa que era a premissa fundamental da economia clássica, segundo a qual o dinheiro, em última instância, seria regulado pelo espectro 
material da equação entre escassez e abundância dos objetos de mercado.

A propriedade fundamental da monetarização é o fato de que, nela, o dinheiro opera como elemento nivelador, equalizando a variedade qualitativa das coisas ao espectro do valor monetário, cuja variação é tão somente quantitativa. Ao se tornar meio universal para todas as trocas, o dinheiro rapidamente deixa de ser meio para ser fim universal. O dinheiro vem a ser o substituto equivalente para todas as coisas: ele se transforma numa espécie sombria de significante universal; torna-se princípio fundamental de redução e simplificação do heterogêneo. A tragédia da cultura de que fala Simmel (1998, p. 34) é correlata ao tornar-se conceito do dinheiro, à sua passagem para significante universal de todas as coisas e relações. Ele atesta a vulgaridade homogeneizante do dinheiro em oposição a uma nostálgica e aristocrática individualidade perdida).

A modernidade ocidental, em função da monetarização da vida e dos processos de objetificação e despersonalização associados a ela, é revelada por Simmel como tragédia da cultura. Isso porque a subjetividade humana, em última instância criadora dos produtos culturais, vê-se perdida e afastada - alienada - de seus próprios produtos e exteriorizações, convertendo-se ela mesma em coisa objetificada, massificada, des-subjetivada. Entre os diversos produtos da ação humana, o dinheiro veio a ser aquele que mais contribuiu para esse estranhamento entre o sujeito e seus produtos. Simmel (2004, p. 474) chega a comparar o dinheiro à corrente sanguínea, "cuja circulação contínua permeia todos os meandros dos órgãos do corpo e unifica suas funções": a dinamização da divisão do trabalho possibilitada pelo incremento monetário conduz a um quadro em que o cultivo de objetos deixa de significar o cultivo concomitante da própria subjetividade ou alma, para implicar, antes, em seu definhamento e dissolução no anonimato da produção em série e do valor monetário. Diz Simmel (2004, p. 464-465):
O processo de objetificação da cultura que, baseado sobre a especialização, provoca um crescente estranhamento entre o sujeito e seus produtos invade em última instância mesmo os aspectos mais íntimos de nossa vida cotidiana. [...] O homem moderno é então rodeado senão por objetos impessoais, de modo que ele se torna cada vez mais condicionado para aceitar a ideia de uma ordem social despersonalizada - embora, é claro, ele também possa se opor a ela. Os objetos culturais crescentemente evoluem para um mundo fechado e interconectado que tem cada vez menos pontos nos quais a alma subjetiva pode interpor sua vontade e seus sentimentos. E esta tendência é mantida por uma certa mobilidade autônoma por parte dos objetos.

Uma vez que o dinheiro deixa de ser o meio da troca para tornar-se o fim de todas as trocas, muda-se também, fundamentalmente, a estrutura da própria troca econômica. Haesler situa esse processo de inversão do caráter da troca no interior do debate entre materialismo e nominalismo sobre a natureza do valor monetário. A racionalização formal das trocas econômicas ratificou o ensejo nominalista segundo o qual o valor monetário não tem lastro material. Haesler (1995) descreve, de maneira sistemática, o que seria um processo de nominalização do valor monetário. Outrora, a troca determinava o uso do dinheiro, regulava a dissensão do valor atribuído às mercadorias: o trocado era sempre o excedente de uma sociedade daquilo que carecia a outra. O dinheiro, diz Haesler (1995), era, nesse caso, uma representação do excedente em relação ao que havia de escasso. Com a disseminação do dinheiro como meio universal e finalidade última de todas as trocas, o processo concreto da troca torna-se objeto de uma representação abstrata que "des-diferencia" a qualidade das coisas em relação à sua escassez ou abundância, para torná-las substituíveis tão somente pela designação quantitativa de um só valor: o monetário. Tal processo é posto a partir da seguinte fórmula: $M=f(T) \rightarrow T=f(M)$. Na primeira parte da fórmula, a moeda $\mathrm{M}$ é compreendida de maneira funcional, como mediador capaz de responder ao crescimento das trocas (T), 
enquanto, na segunda equação, a troca assume um caráter substancial, e deve ser sempre de tal maneira que realize a operação $M \rightarrow M$, onde M' > M. Nos termos de Haesler, a troca, segundo a última equação, não teria lugar senão na medida em que permitisse a expansão de $M$ em M'(Haesler, 1995, p. 51).

Entre tantas consequências apontadas por Simmel e Haesler no que toca a esse fenômeno, nos interessam sobremaneira três delas, já que condicionam toda a estrutura da moderna economia global:

a) Uma vez o dinheiro tornado significante universal para todas as coisas, uma vez tornado o "instrumento dos instrumentos", sua existência depende de um crescimento fantasmático que não diz respeito ao setor produtivo da economia: se Marx desvendara o processo de mais-valia no setor produtivo, Simmel e Haesler estão a desvendá-lo nas relações de circulação. O dinheiro só existe em função de seu crescimento, que deve ser efetuado, como uma "Lei da criação", a cada troca;

b) Uma vez que o crescimento monetário torna-se a meta última da ordem social e econômica, o dinheiro e seu crescimento nominal tornam-se o único princípio de realidade: ele vem a ser o referencial primeiro que conduz todas as possibilidades de objetivação do mundo; e

c) No quadro de um expansivo crescimento nominal do dinheiro, o próprio mundo, em sua diversidade, toda coisa, todo ser ou relação passam a ser considerados como uma hipóstase do dinheiro.

É já nesse quadro que se inserem as novas técnicas monetárias e a monética. Elas o racionalizam segundo a lógica da racionalização formal. Com a situação posta pelo processo de monetarização da economia e nominalização crescente do dinheiro, a possibilidade de criação artificial de dinheiro a partir da fidúcia, da confiança, do crédito dado àquele que compra sem ter o que vender (ou dar em troca), a circulação passou a ser, no século XX, a esfera por meio da qual se resolveram os problemas financeiros das crises de produção. A racionalização formal, nesse caso, vai além das relações sociais de produção, ligadas à organização racional do trabalho, à burocratização dos setores produtivos e administrativos, e passa a se intensificar principalmente no modo de realização das trocas econômicas. Esse processo de racionalização formal a presidir, mais do que a produção, também as trocas econômicas, é prenhe de consequências para a ordem global na qual passa a se configurar o capitalismo. A principal consequência está longe de partilhar o otimismo de um Anthony Giddens (1991, p. 79-80), quando afirma que:

\begin{abstract}
A globalização pode assim ser definida como a intensificação das relações sociais em escala mundial, que ligam localidades distantes de tal maneira que acontecimentos locais são modelados por eventos ocorrendo a muitas milhas de distância e vice-versa. [...] A transformação local é tanto uma parte da globalização quanto a extensão lateral das conexões sociais através do tempo e do espaço. Assim, quem quer que estude as cidades hoje em dia, em qualquer parte do mundo, está ciente de que o que ocorre numa vizinhança local tende a ser influenciado por fatores - tais como o dinheiro mundial e mercados de bens - operando a uma distância indefinida da vizinhança em questão.
\end{abstract}

Embora Giddens (1991) reconheça o dinheiro como uma variável fundamental da globalização - aquela que, por excelência, permite um "alongamento" das relações sociais e a influência à distância de contextos que, dissolvidos na estrutura monetária da economia global, se "desencaixam" -, ele parece não perceber o essencial desse processo. Ora, essa suposta intensificação das relações sociais se dá à custa de uma mudança fundamental da estrutura de reciprocidade da relação social ou do que Haesler (1995), seguindo Simmel, chama de sociabilidade primária. O resultado fundamental do processo de racionalização formal que altera a estrutura da reciprocidade é, para Haesler (1995), a monética, a eletronização dos fluxos monetários e a invenção dos cartões magnéticos e dos meios digitais de pagamento: nesse caso, 
a troca sofre uma série de racionalizações subsequentes àquelas já introduzidas pelo dinheiro-moeda como meio facilitador das trocas. A principal racionalização em questão diz respeito à crescente desmaterialização do dinheiro: o tornar-se conceito do dinheiro, sua nominalização, evidenciada por nós mais acima, permite a ulterior cifragem e digitalização do dinheiro como informação cifrada (do código de barras à transferência imediata de informações cifradas referentes a limites de crédito e débito). Com os cartões, o que se troca são informações cifradas de valores nominais.

A implicação central da desmaterialização do dinheiro é que, se desmaterializando, ele se invisibiliza. Na era das transações econômicas digitais, mediadas não mais pela moeda material, mas por senhas de cartões, ocorre o que Haesler chama de indolorização do sacrifício: a aquisição de um bem não corresponde mais à percepção de um sacrifício correspondente, pois os dois polos do esquema reciprocitário são separados e reinscritos em outra ordem de valorização. O que Giddens não vê, portanto, é que a suposta intensificação das relações sociais da qual fala depende, antes, da progressiva dissolução do esquema reciprocitário da ação. O que cabe perguntar é se, diante desse novo quadro da economia global, falamos ainda de ação e relação social em seu esquema da sociologia clássica.

Na verdade, [...] a interação não tem mais lugar, o esquema reflexivo da ação, a antecipação cognitiva das suas consequências e o levar em conta as antecipações dos outros, são substituídos por um esquema transacional de ações. Assim, a norma de base da sociedade de mercado seria posta fora do jogo. $\mathrm{Mu}$ dança imperceptível em nossas práticas cotidianas, esta desintegração da troca praticada e vivida inauguraria uma reestruturação integral de nossos sistemas sociais. [...] Ora, parece que nós assistimos pela primeira vez na história da humanidade a tentativa de edificar uma ordem social sem troca, uma ordem social onde não seria mais demandado aos homens imaginar as formas de vida mútua e de articulá-las reflexivamente, mas apenas se conformar às coisas pré-estabelecidas e opções comandadas à distância (Haesler, 1995, p. 47).
Ao menos duas outras consequências de grande abrangência é preciso destacar aí. A primeira delas é que a rede digital de valores nominais cria uma espécie de semiótica universal como a "nova economia política" do mundo globalizado. É uma tal rede que tornará a produção de riquezas como um puro movimento de informações, "permitindo pôr em circulação toda a riqueza semiológica do mundo" (Haesler, 1995, p. 168, tradução nossa). A racionalização formal das trocas e da circulação deixa a encargo do setor bancário o gerenciamento do espaço virtual de troca de informações e cifras que constitui o mercado financeiro global. Um dos principais elementos dessa racionalização, operada, a princípio, pela gestão bancária, foi a constituição do cartão como meio de pagamento, tornando-o mediador central das trocas na era da eletronização dos fluxos monetários e da nova ordem econômica globalizada.

Os cartões, como elemento fundamental das novas técnicas monetárias, constituem um conjunto denso de consequências para a sociedade globalizada. Ele implica mudanças antropológicas e societárias de longo alcance, tanto no aspecto micro quanto no macrossociológico. Em sentido antropológico, os cartões, diz Haesler, simulam a "re-personalização" do dinheiro, algo que "lembra certos aspectos das moedas arcaicas que não podiam ser emitidas ou possuídas senão por pessoas qualificadas" (Haesler, 1995, p. 76, tradução nossa). No âmbito propriamente sociológico e econômico, o cartão e a monética implicam a penetração da racionalidade formal num ambiente no qual ela permanecia distante: se um dos fatores essenciais de distinção da época moderna, no âmbito da economia, foi a separação entre empresa e comunidade doméstica (Weber, 2004, p. 261), a monética permite agora que também o orçamento doméstico, paraíso perdido do descanso e do lazer (das pequenas irracionalidades íntimas), da fuga da rotina massiva do trabalho e suas exigências vitais, fosse racionalizado e gerido segundo princípios técnicos 
(destaque para o surgimento de disciplinas tecnicamente especializadas como a "economia doméstica”), possibilitados pelo aumento do controle dos fluxos de capitais a cada transação econômica eletronicamente efetuada.

Como foi dito, o cartão corresponde a uma ferramenta técnica de altíssima eficiência, o que lhe dá o estatuto de princípio de unidade organizacional dos diversos setores de atividade. Surgido inicialmente como ferramenta de pagamento, o cartão se revelou como a substância fundamental de controle de informações que o anonimato despersonalizado do dinheiro mantinha sigilosas. Mais do que o registro detalhado dos fluxos monetários - com a monética, o dinheiro se torna memorizável em todos os seus movimentos - o cartão permite ainda uma espécie de "inteligência documentar" que registra a variedade personalizada dos hábitos de consumo.

Mas a racionalização formal operada pela monética vai ainda mais longe. $\mathrm{O}$ cartão levou também a uma espécie de desintegração das fronteiras entre o setor bancário, o setor produtivo e os órgãos estatais. Se, entre os autores marxistas atuais, é comum o destaque da dissolução derradeira das fronteiras entre os Estados e as empresas, o cartão aponta para uma unidade organizacional que inclui o setor F bancário como instância fundamental de gesخे. tão e controle dos fluxos monetários e, nessa $\dot{\circ}$ medida, das relações econômicas em geral. O Estado passa a existir não só como organizador das condições gerais de produção, mas como gestor da circulação; enquanto a máquina do Estado deve servir à infraestrutura das condições de produção e à capacitação técnica da mão de obra (as condições gerais de produção), हे o banco central de cada Estado passa a definir $\vec{*}$ as margens de nominalização e crescimento do dinheiro em função da capacidade (potencializada pelo crédito) de consumo. da racionalização, pode-se imaginar que todo esse quadro de racionalização suplementar do capitalismo seja acompanhado de um rol pou- co ou nada conhecido de "irracionalizações". É fácil compreender também que ele redunde numa disciplinarização complementar: caminha-se, a passos largos, para a constituição de uma sociedade na qual o poder não se exerce mais pelo exterior, a partir de uma disciplina imposta pela força de órgãos burocráticos encarregados de manter a ordem, mas pelo interior, dado que o autocontrole, segundo a orientação da normatividade técnica, deve ser uma variável crescente do agir para que se tenha êxito em qualquer ação no mundo hipermonetarizado da globalização.

Chamamos a atenção do leitor para o qualificativo "suplementar". É suplementar porque se segue a uma diversidade de processos racionalizadores e disciplinadores anteriores. Norbert Elias (1996), em O processo civilizador: formação do Estado e Civilização, livro publicado primeiramente em 1939, já destacava a dimensão do autocontrole como fundadora da subjetividade moderna e o modo como tal dimensão já operava incisivamente na personalidade humana em decorrência do surgimento do Estado moderno, weberianamente entendido como instituição monopolizadora da violência:

A compulsão real é a que o indivíduo exerce sobre
si mesmo, seja como resultado do conhecimento das
possíveis consequências de seus atos no jogo de ati-
vidades entrelaçadas, seja como o resultado de ges-
tos correspondentes de adultos que contribuíram
para lhe modelar o comportamento em criança. A
monopolização da violência física, a concentração
de armas e homens armados sob uma espécie de au-
toridade, torna mais ou menos calculável o seu em-
prego e força os homens desarmados, nos espaços
sociais pacificados, a controlarem sua própria vio-
lência mediante precaução ou reflexão. Em outras
palavras, isso impõe às pessoas um maior ou menor
grau de autocontrole (Elias, 1996, p. 201).

Ora, pode-se assim dizer que o processo civilizador, destacado por Elias como uma racionalização ou disciplinarização e um autocontrole crescente exercido pelos indivíduos sobre si mesmos, ganhou desdobramentos e reforços ulteriores ligados ao desenvolvimento 
do capitalismo, cujo funcionamento seleciona (e, portanto, pune e exclui) indivíduos não aptos a exercer uma função sistêmica - isto é, indivíduos não disciplinados no autocontrole.

Se o dinheiro já apontava, desde Simmel, se transformar numa espécie de linguagem universal da qual todas as coisas da cultura objetiva não eram senão uma hipóstase, com Haesler a invisibilização do dinheiro e sua digitalização cifrada, o dinheiro como o invisível princípio de realidade das coisas, funda uma nova estética transcendental, uma vez que desloca substancialmente os julgamentos sintéticos a priori (tempo e espaço) da apercepção transcendental para o dinheiro. Na economia hipermonetarizada, as categorias do pensamento são instrumentalizadas pelas categorias próprias ao dinheiro. O insight fundamental, aí, Haesler o toma de Bruno Liebrucks, filósofo alemão que, nesse quesito, anteciparia as reflexões de Hans Blumenberg sobre a natureza do dinheiro como novo princípio cognitivo.

\footnotetext{
Mas se, em Kant, a objetividade reside precisamente na relação da multiplicidade à unidade da apercepção transcendental, onde habita/permanece a coisa? A coisidade da coisa não é dada pelos sentidos, mas provém da unidade da apercepção transcendental. Esta coisidade é o que impede nosso conhecimento de ser senão a posteriori. A coisidade da coisa é a condição de possibilidade dos julgamentos sintéticos a priori. Mas, neste caso, não é o homem que pensa, mas o dinheiro. O Rei Midas devia ao menos tocar ainda as coisas a fim de que elas se transformassem em ouro. No caso presente, o homem pensa já as coisas enquanto dinheiro. O dinheiro é absoluto, e, enquanto o homem o pensa como absoluto, ele se pensa a si mesmo (Haesler, 1995, p. 24, grifo do autor).
}

Com a hipermonetarização da economia, passa a ser o dinheiro, e não mais a "apercepção transcendental”, o elemento ativo que dá inteligibilidade à coisidade da coisa. A sensibilidade e os juízos sintéticos a priori passam a ser correlatos não mais à subjetividade transcendental que liga as formas intuitivas às categorias do entendimento, mas ao princípio formal e quantitativo do dinheiro em sua forma nominal. O pensar as coisas na forma do dinheiro, do "quanto vale" em dinheiro, vem a ser uma espécie de $a$ priori do pensamento que é correlato ao tornar-se linguagem do dinheiro. As práticas do cartão de crédito, inseridas nesse processo, alteram fundamentalmente o tempo e o espaço com relação à efetuação das trocas e à objetivação dos objetos de desejo a partir do dinheiro.

Com relação ao tempo, a monética introduz, em primeiro lugar, a imediaticidade da transação monetária, o que, em circunstâncias de comércio anteriores, levava dias em processo de certificação e efetuação monetária dos objetos trocados. Se a racionalidade formal já havia, segundo Castoriadis (2004), reduzido fundamentalmente a duração ao tempo homogeneizado "imposto a todos", a imediaticidade das transações monetárias, permitida pela eletronização e informatização dos fluxos monetários, inverte, ainda, a famosa constatação de Benjamin Franklin de que "Tempo é dinheiro", numa mais complexa e paradoxal forma: "Dinheiro é tempo". Aquele que detém dinheiro pode comprar o tempo dos outros, pode, em outras palavras, fazê-los esperar:

O que é verdade, pelo contrário, é que o dinheiro é o tempo. E eis aí uma mensagem essencial que nos deixaram pensadores tão diferentes como Keynes e Simmel; aquele que o tem, pode fazer esperar os outros, ele pode agarrar a ocasião que se apresenta e ele pode fazer projetos. O dinheiro permite antecipar, 'ter o dinheiro significa ter um futuro', disse ainda Niklas Luhmann. E é aí que reside o motivo central da instituição do crédito (Haesler, 1995, p. 92).

Com a crescente nominalização do valor monetário, somada à eletronização dos fluxos monetários possibilitada pela monética, a imediaticidade temporal das transações inscreve, paradoxalmente, a troca em dois registros temporais diferentes. No mercado tradicional, o consumo e sua regulação são realizados num só ato, através da troca mediada pelo dinheiro. A transação por cartões, por sua vez, põe em cena um registro temporal duplo e autoexcludente, que é o tempo da escolha e o tempo do regulamento - o pagamento - da troca. Haesler nos fala, a partir disso, de uma crescente "des- 
-futurização" do futuro, correlata à banalização do crédito. Para Haesler, a relação de fidúcia e confiança que preside as novas relações de crédito não se liga mais à antiga etimologia de con-fidere. Ao contrário, quanto mais a monética simplifica a complexidade das relações de troca e seus potenciais conflitos e resistências, mais desconhecemos os processos e os mecanismos que regulam o sistema monetário internacional. A confiança, há muito, degenerou-se em abandono. O futuro torna-se crescentemente representável tão somente pelas dívidas que contraímos em transações efetuadas num presente imediato. E a esse futuro incerto, diz Haesler, corresponde um presente imediatizado, no qual o consumo se transformara na forma fundamental da consumação ou efetivação de si. O momento de êxtase e de revelação da antiga concepção kairológica de tempo - como o tempo da experiência do momento oportuno, no qual a decisão ou criação intervém criativamente no tempo linear, objetivo -, a consumação (consumation) e efetivação de si no presente, degenera-se em consumo (consommation) como única forma de efetivação de si no presente:

Sombra do momento que passa, da dádiva desperdiçada, [...], o presente-aí tem do kairos antigo que perdera apenas o momento de êxtase e de revelação. O presente-aí é um momento pontual onde aflui toda a energia que, em seguida, se derrama/transborda no mundo do projeto, do imaginário e do fantasma. No presente, o fantasma se realiza e se autodestrói de uma só vez, formidável descarga de energia que se aniquila instantaneamente. O consumo transforma-se completamente, portanto, em consumação, não de valores de mercado, mas de energias pessoais que não conseguem se realizar senão nessa cotidianidade miserável do supermercado (Haesler, 1995, p. 94).

Se as operações encartadas, como as nomeia Haesler, imprimem tal variação na estrutura temporal das relações sociais, elas realizam algo semelhante no que diz respeito ao espaço. Logo que o consumo se tornou uma forma de consumação, de efetivação de si no presente existencial, com o correlato comprometimento do futuro, também a distância entre nós e os objetos de consumo sofreu modifi- cações fundamentais. Na verdade, tal distância, que havia antes entre nós e os objetos de consumo que permeavam nossos desejos, deixa gradativamente de existir com os cartões de crédito. São exatamente os obstáculos entre os objetos de desejo e sua realização que o sistema de crédito monetário suplanta. Ora, esses dois aspectos da eletronização dos fluxos monetários, para Haesler, estão entre os principais fatos da dissolução do esquema reciprocitário da ação, assinalado por nós mais acima. Escrito em 1995, esse é um diagnóstico que se radicaliza graças às novas racionalizações que culminam, nos dias atuais, na telemática. Não seria impertinente, num outro trabalho, compreender a telemática como uma das pontas desse processo de racionalização (formal) das trocas que descrevemos até aqui. O aparecimento crescente de vários setores de atividades ligados aos chamados teletrabalhos confirma a pertinência da hipótese e a proficuidade de um tal estudo que deverá se seguir a este.

Tratou-se, aqui, simplesmente de remeter o quadro atual do mundo globalizado, num dos seus aspectos centrais, a categorias que já estavam sendo desenvolvidas há quase um século atrás, atestando, assim, a despeito de toda ruptura gerada por uma nova racionalização, certa continuidade no processo e uma ausência de limites claros entre uma era industrial e outra pós-industrial: ambas são desdobramentos da racionalização formal. Racionalização formal e monetarização, nessa medida, são tendências de desenvolvimento que dão sequência às novas formas de sociabilização iniciadas pela era moderna. A globalização, por isso, é sua contraparte empírica, o efeito não intencional da realização concreta dessas tendências. Ela incumbe, portanto, todas as ciências humanas ao contato abrupto com esse problema, para o qual este artigo, entre outras coisas, pretendeu oferecer uma modesta contribuição e um direcionamento específico.

Recebido para publicação em 09 de junho de 2016 Aceito em 31 de julho de 2017 


\section{REFERÊNCIAS}

BECK, U. Liberdade ou capitalismo: Ulrich Beck conversa com JohannesWillms. São Paulo: UNESP, 2002.

CASTORIADIS, C. A racionalidade do capitalismo. In: CASTORIADIS, C. Figuras do Pensável: as encruzilhadas do labirinto.Rio de Janeiro: Civilização Brasileira, 2004. v. 6.p. 87- 124.

CIAFFA, J. Max Weber and the Problem of Value-Free Social Science: A Critical Examination of Wertulteilsstreit. Canbrury: Associated University Press, 1998.

ELIAS, N. O processo civilizador: formação do Estado e Civilização. Rio de Janeiro: Jorge Zahar, 1996.

GIDDENS, A. As consequências da modernidade. São Paulo: UNESP, 1991.

HABERMAS, J. Teoría de la acción comunicativa I. $3^{\mathrm{a}}$ ed. Madrid: Taurus, 1999.

HAESLER, Aldo. Sociologie de l'argent et postmodernité. Genève: Librairie Droz, 1995.

IANNI, O. Teorias da globalização. Rio de Janeiro: Civilização Brasileira, 2001.

IANNI, O. A era do globalismo. Rio de Janeiro: Civilização Brasileira, 2004.

JAMESON, F. A cultura do dinheiro: ensaios sobre a globalização. Petrópolis: Vozes, 2002.

KALBERG, S. Max Weber's Types of Rationality: Cornerstones for the Analysis of Rationalization Processes in History. American Journal of Sociology, Chicago, v. 85 n. 5, p. 1145-1179, 1980.

KOSHUL, B. B. The Postmodern Significance of Max Weber's Legacy. New York: Palgrave Macmillan, 2005.
LÖWITH, K. Max Weber y Karl Marx.Barcelona: Editorial Gedisa, 2007.

MARCUSE, He. Negations: Essays in Critical Theory. London: MayFly, 2009.

SCHLUCHTER, W. TheRise of Western Rationalism: Max Weber's Developmental History. California: University of California Press, 1981

SCHLUCHTER, W. xParadoxos da modernidade. São Paulo: UNESP, 2010.

SICA, A. Max Weber and the New Century. New Jersey: Transaction Publishers, 2004.

SIMMEL, G. Philosophy of Money. New York: Routledge, 2004

SIMMEL, G. O Dinheiro na Cultura Moderna. In. SOUZA, J.; ÖELZE, B. (Org.). Simmel e a modernidade. Brasília: UnB, 1998. p. 23-40.

WEBER, M. Economia e Sociedade. São Paulo: Ed. UnB, 2004.v. 1.

WEBER, M. Ensayos de la Sociología de la Religión I. Madrid: Taurus Humanidades, 1992.

WEBER, M. A Ética Protestante e o "Espírito" do Capitalismo.São Paulo: Companhia das Letras, 2007.

WEBER, M. The meaning of value freedom in sociological and economic sciences. In:BRUUN, H. H.; WHIMSTER, S. Max Weber: Collected methodological writings. Translation ofHans Henrik Brunn.London: Routledge, 2012a. p. 304 $-334$.

WEBER, M. The "objectivity" of knowledge in social science and social policy. In:WEBER, M. Max Weber: Collected methodological writings. Translation of Hans Henrik Brunn. London: Routledge, 2012b. p. 100-138. 


\section{RATIONALIZATION AND MONETIZATION: categories of globalization}

\section{Ulisses do Valle}

This article aims to analyze some aspects of central dimension in the phenomenon often known as globalization. The main objective is to understand the global monetary economy according to two fundamental categories of sociology: rationalization (Max Weber) and monetization (Georg Simmel). Based on this, we will present some ideas of the French-Swiss sociologist Aldo Haesler regarding the consequences of the electronization of monetary flow that is in the bases of globalization. Among other aspects, Haesler draws attention to the systematic correlation of three fundamental aspects associated with the global monetary economy: the invisibility of money, the painlessness of the sacrifice made in economic exchanges, and the dissolution of the reciprocal scheme of action.

KeYwORDS: Rationalization. Monetization. Money. globalization. Aldo Haesler.

\section{RATIONALISATION ET MONÉTARISATION: catégories de la mondialisation}

\section{Ulisses do Valle}

Cet article se veut d'analyser certains aspects de la dimension centrale du phénomène souvent connu sous le nom de mondialisation. Il s'agit de comprendre l'économie monétaire mondiale à la lumière de deux catégories fondamentales de la sociologie: la rationalisation (Max Weber) et la monétarisation (Georg Simmel). Sur cette base, nous présenterons quelques idées du sociologue francosuisse Aldo Haesler, concernant les conséquences de la digitalisation des flux monétaires qui est à la base de la mondialisation. Haesler attire l'attention, entre autres, sur la corrélation systématique de trois aspects fondamentaux associés à l'économie monétaire mondiale: l'argent invisible, le sacrifice indolore dans les échanges économiques et la dissolution du schéma d'action réciproque.

MotS-CLÉs: Rationalisation. Monétarisation. Argent. Mondialisation. Aldo Haesler. de Goiás. Sua tese de doutorado tematizou centralmente a obra de Max Weber, autor clássico sobre o qual prepara livro intitulado "Max Weber: teoria da História" e sobre o qual tem artigos publicados, entre os quais se destaca "As relações entre história e sociologia no horizonte da conceitualização e explicação de objetos históricos" (Revista História e Cultura). Além disso, tem publicado artigos sobre pensamento social brasileiro, entre os quais se destacam: "Sérgio Buarque de Holanda leitor de Heidegger? reflexões sobre um paradoxo do personalismo do homem cordial” (Revista de História da Historiografia), "Personalismo e exterioridade: a busca do ser-brasileiro e o dilema da autenticidade" (Revista de Teoria da História) e "A Filosofia da História de Oswald de Andrade (Revista Remate de Males). 